\title{
Geoinformation Sharing System for East and Southeast Asia Using SDI, OGC Web Services and FOSS
}

\author{
Joel Bandibas, Shinji Takarada \\ Geological Survey of Japan, AIST, Tsukuba, Japan \\ Email: joel.bandibas@aist.go.jp
}

How to cite this paper: Bandibas, J. and Takarada, S. (2019) Geoinformation Sharing System for East and Southeast Asia Using SDI, OGC Web Services and FOSS. International Journal of Geosciences, 10, 209-224.

https://doi.org/10.4236/ijg.2019.102013

Received: January 30, 2019

Accepted: February 25, 2019

Published: February 28, 2019

Copyright $\odot 2019$ by author(s) and Scientific Research Publishing Inc. This work is licensed under the Creative Commons Attribution International License (CC BY 4.0).

http://creativecommons.org/licenses/by/4.0/

(c) (i) Open Access

\begin{abstract}
This paper presents an innovative, cost-effective and efficient web-based sharing system for geoscience information among the countries in East and Southeast Asia. The information system's main components are organized following the Spatial Data Infrastructure (SDI) model. It also uses the Open Geospatial Consortium (OGC) Web Map Service (WMS) and Web Processing Service (WPS) for online spatial data rendition and processing, respectively. Free and Open Source Software (FOSS) are also used for other important spatial data processing functions. The geospatial contents of the information system are stored and managed using the open source software PostgreSQL and its PostGIS extension. The information system makes spatial data sharing more efficient and organized by formulating a hierarchical information content classification scheme and the option for the users to put up their own customized WebGIS portals. These give users the option to show their chosen geospatial contents on their own web-based platform. The information system also makes spatial data sharing more flexible by providing data owners the choice to determine the data access privileges for each user or group of users. It also provides module for processing, rendering and sharing Japan's ASTER satellite images. The information system is called GSi for Geoinformation Sharing Infrastructure for East and Southeast Asia. The URL of the web-based information system is https://ccop-gsi.org/main/index.html.
\end{abstract}

\section{Keywords}

WebGIS, SDI, FOSS, OGC, WMS, WPS, Geoinformation Sharing

\section{Introduction}

Geoscience information is an indispensable input for the important undertak- 
ings to protect the environment, mitigate the effects of natural disasters, and manage and sustain the use of natural resources. These kinds of activities are not restricted by national boundaries. Hence, the availability of geoscience data among the countries in a region is very important. Developing an information system for sharing geoscience information requires the use of Geographic Information System (GIS) software to make it more efficient and cost-effective for spatial information processing, management and storage [1] [2]. Almost all kinds of human activities require the use and processing of geographically referenced information. Hence, GIS is an indispensable tool for a broad range of research disciplines in the biological, social and physical sciences (e.g. [3]-[9]). Conventional GIS system is installed in standalone computer where the spatial data are also stored. Users who want to do spatial information processing should have physical access to this computer. This kind of spatial information system is starting to become obsolete in meeting the increasing need for geospatial content and geospatial information processing of many organizations. Indeed, sharing huge volume of geoscience information using this kind of system will be inefficient and expensive. Accessing geoscience information and GIS software that are saved and installed, respectively, in a remote server becomes the norm in recent years. This kind of setup makes geoscience information and spatial data processing services highly accessible to many users, who just need internet access to run the GIS system and use the data anywhere in the world. Furthermore, computationally expensive geospatial information processing using devices with low processor speed, Random Access Memory (RAM) and storage capacity like mobile phones is possible, because information processing and storage are implemented in the remote server. The information system is generally called Web-based Geographic Information System (WebGIS). It is assigned with a Universal Resource Locator (URL) that users can use to access the spatial information processing service. A wide range of research undertakings using geospatial data use this kind of spatial information system (e.g. [10] [11] [12] [13]). WebGIS has been developed and used extensively in real-world applications [14]. It is widely used to efficiently share geographically referenced data in many disciplines. Gao [15] worked on a WebGIS system for health information sharing while Chen et al. [16] developed an innovative Web-based GIS in disseminating flood information. Jian et al. [17], on the other hand, implemented the geological environment data management information system (GEMIS) based on WebGIS to manage and share geological hazard data. Charoenbunwanon et al. [18] works on the use of WebGIS for sharing Thailand's mineral resources information. Developing an efficient and cost-effected WebGIS system for sharing huge volume of geospatial information from geographically distributed data sources requires the formulation of web services that provide spatial information management and processing functions. Users access the GIS software and geospatial contents by sending requests to these web services, which serves as the go between the GIS software and spatial database and the users. Users access the web services by sending request in a form of Universal Resource Identifier (URI) 
using a web browser. The selected web service will do the requested geoinformation processing and send back results that are either geographically referenced map images or xml documents. However, using these web services to process geospatial information from diverse sources is difficult because of the differences in data formats and projections. Hence, WebGIS will just work when standards are used for spatial information sharing. The Open Geospatial Consortium (OGC) has been setting standards for sharing geographically referenced data though the World Wide Web. The OGC Web Map Service (WMS) and Web Processing Service (WPS) are the mainstream web services standards for sharing map images and processing geospatial contents online, respectively [19]. Web-based spatial information systems are generally organized following Spatial Data Infrastructure (SDI) model [20], wherein a system is conceptualized as a 3-layered system (Figure 1). The 3 layers of an SDI, from top to bottom, are the user and applications (top layer), geospatial web services (middle layer) and geospatial contents (bottom layer). Geospatial services layer provides a wide array web services for data rendition and processing. Many of these web services access the geospatial content layer where the spatial database resides. SDI was conceptualized to make the sharing of geospatial contents through the World Wide Web easy to implement and efficient [21]. Its implementation for governments and companies has gained ample attention in recent years [22] primarily because environmental problems demand information system that makes spatial data readily available to decision makers [23]. The Infrastructure for Spatial Information in Europe (INSPIRE) of the European Union (EU) showcases a successful use of SDI in sharing huge volume of information among EU countries [24].

The economies of the countries in East and Southeast Asia have been growing at a faster pace for many years. On the other hand, natural disasters sweep through many countries in the region more often than any region in the world. Sustaining economic growth while protecting the environment and mitigating the effects of natural disasters require easily accessible geoscience information

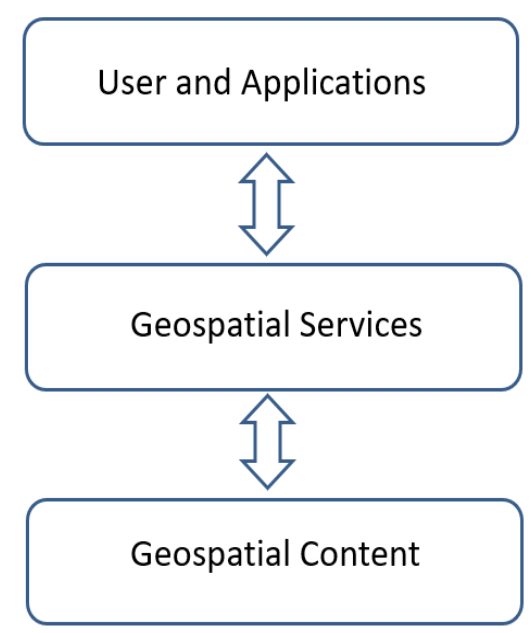

Figure 1. Three-tier architecture of spatial data infrastructure model [20]. 
input for the region's leaders to do informed decision making, and for researchers to produce relevant research results. Thus, developing an advanced information system to make geoscience information from the countries in the region highly accessible and available is very important. This paper presents an innovative, cost-effective and efficient system for sharing geoscience information among the countries in East and Southeast Asia using SDI, OGC web services and Free and Open Source Software (FOSS). The main components of the information system and the web services that users should formulate to share their data online are explained. This paper also outlines the classification of the GSi information contents into information categories, how the shared data are organized following these categories, and the data access permission level of each user or group of users. This paper outlines the flexible and innovative geospatial data sharing concepts of the information system.

\section{GSi Components}

The developed geoinformation sharing system follows the 3-layered SDI architecture. Its 3 major components are the Applications, Web Services and Database (Figure 2). Users access the system's geospatial contents by sending requests to the web services, which serve as the go between the users and the database components. Sharing and integrating spatial information from multiple sources, with different formats and projections, are implemented using OGC

\section{Data Owners}

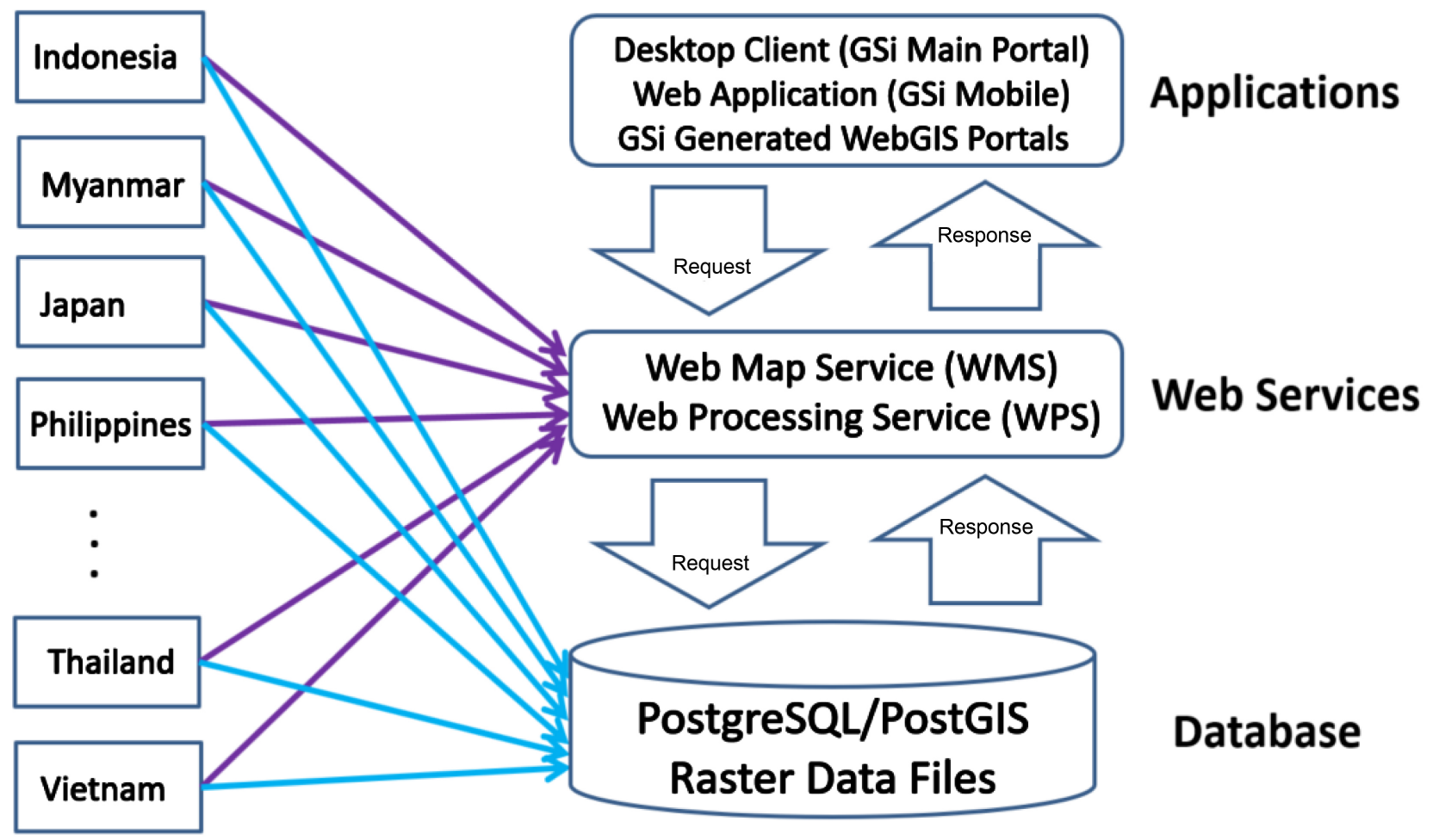

Figure 2. The major components of GSi. 
standards. GSi facilitates the sharing of geospatial information by providing data owners the choice to formulate web services for the data that they share as shown in Figure 2. Data owners upload their data into the GSi database and formulate the web services that applications can use to access the data. The concept makes GSi very useful for researchers and decision makers who want to use geospatial information from multiple sources. Server and client-side specialized scripts are written to construct GSi's major components and organize them into a web-based geoscience information sharing system.

\subsection{Applications}

The GSi Applications component contains the main GSi portal (Figure 3), GSi mobile application and all customized WebGIS portals generated using the information system. These applications provide interface for the formulation of web services requests that will be sent to the web services layer for spatial data rendition and processing. Requests for important data sharing functions like data download and database query are sent by the applications. The applications also serve as WMS clients for viewing maps that are available in the system. Selecting a map on a list will trigger WMS GetMap requests that are sent to the WMS server, which then query the database and return the results as map images for viewing. GSi applications use the open source Leaflet JavaScript library [25] for viewing the maps. The main GSi portal provides an interface for processing ASTER satellite images for sharing and viewing (Figure 4). Users can also use

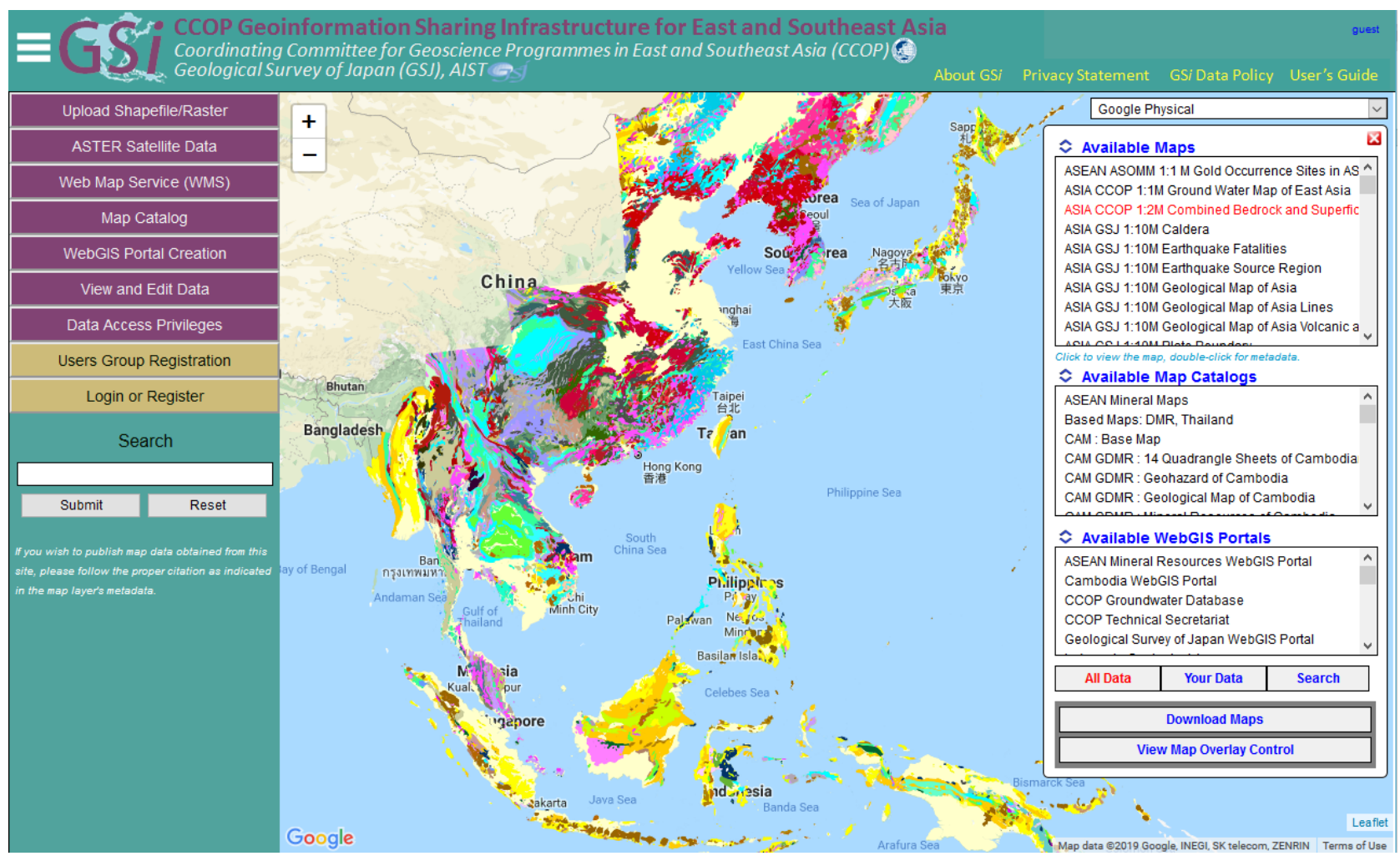

Figure 3. The GSi main page. 


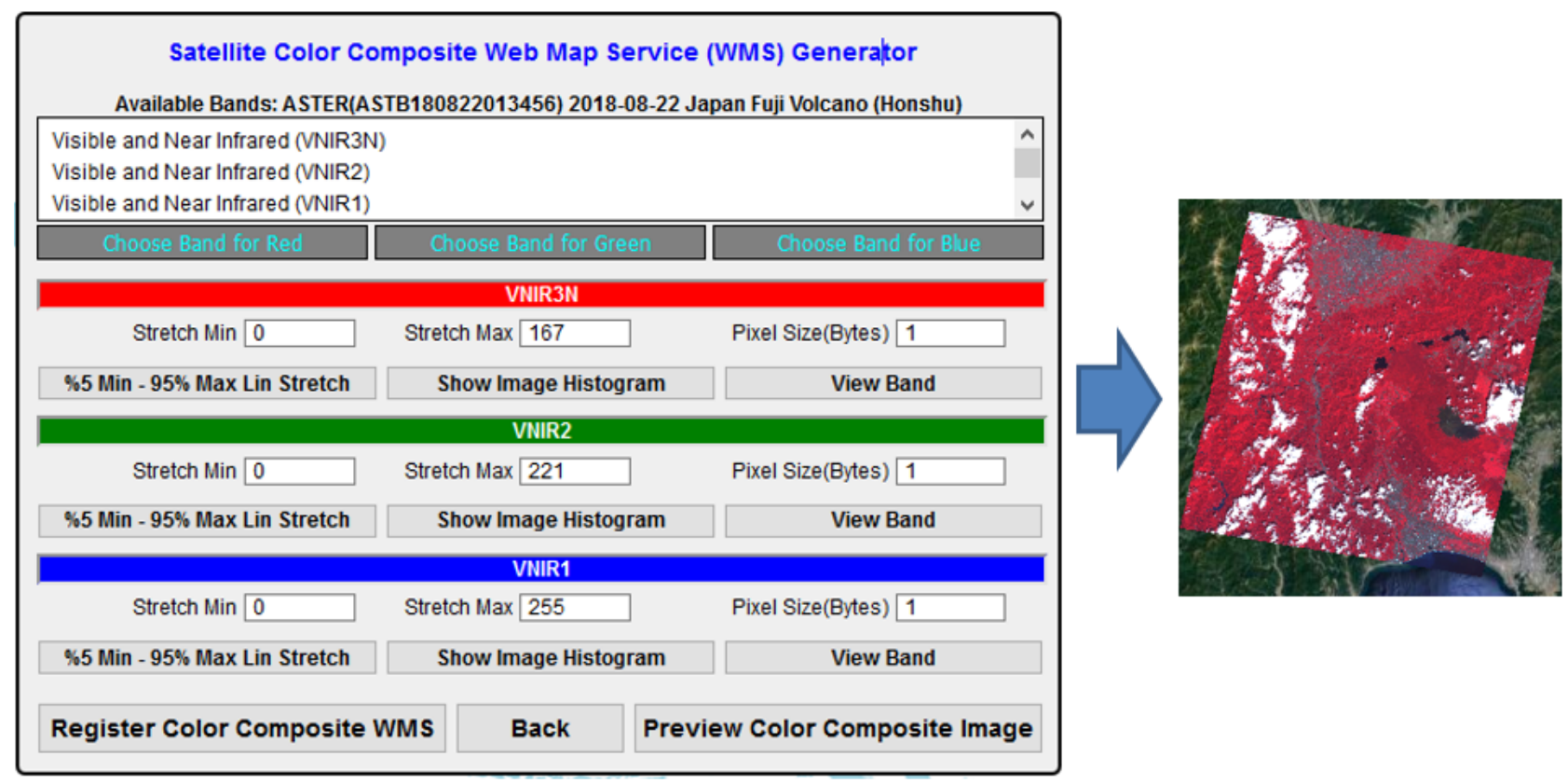

Figure 4. The GSi interface for processing ASTER satellite data.

the site to generate their own customized WebGIS portal to enable them to organize their geospatial contents using their own web-based platform.

\subsection{Web Services}

The GSi Web Services component contains OGC WMS and WPS (Figure 2). These services are assigned with unique Universal Resource Locator (URL) that applications use to avail of the web services functions. The WMS provides a simple Hypertext Transfer Protocol (HTTP) interface for requesting geo-registered map images from one or more distributed databases [26] (Figure 5). To view a map served as WMS, a user should send GetMap request to the WMS server. The request is in the form of Universal Resource Identifier (URI) which includes the URL of the WMS, the extent of the area of the map to be viewed and other important parameters. The WMS server queries the database using the parameters in the URI and returns the query result in the form of geographically referenced map images. Figure 6 shows the WMS GetMap request URI to get and view the map image of the geological map covering East and Southeast Asia. GSi provides interface to enable data owners formulate WMS services for the maps they upload to the GSi database. Figure 7 shows the GSi form to formulate the WMS service for the geological map covering East and Southeast Asia. The information system uses the WMS open source software MapServer [27].

The WPS provides a standard interface that simplifies the task of making simple or complex geospatial processing using HTTP. It provides robust, interoperable, and versatile protocol for process execution of web services [28]. Geoprocessing is executed by sending WPS request, in the form of URI, to the server where PHP scripts written for the tasks are executed. The GSi information 


\section{Geospatial Database}
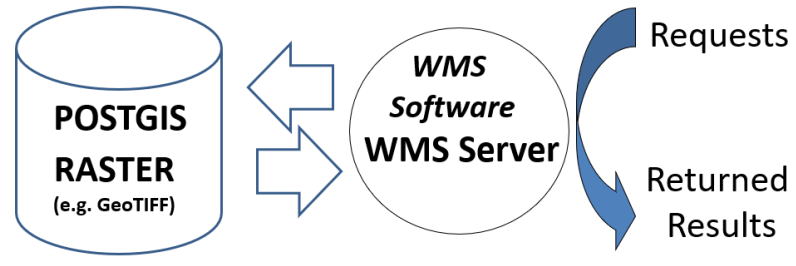

Figure 5. Web map service.

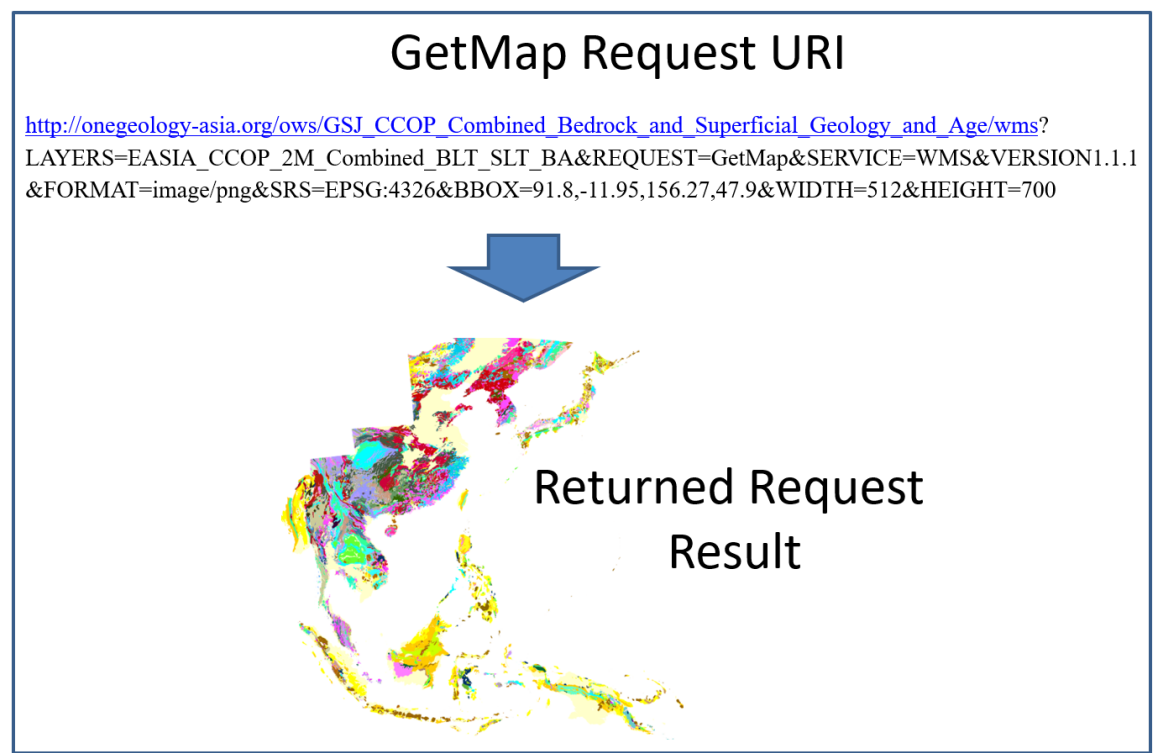

Figure 6. WMS GetMap request URI to get the geological map image covering East and Southeast Asia.

system formulate WPS for important geospatial information sharing functions such as data upload and their entry into the GSi database, and data download.

\subsection{Database}

The most important component of the sharing system is the Database which contains the system's geospatial contents. The system uses the open source relational database management system software PostgreSQL [29] and its PostGIS extension [30] for the storage of GSi data. Figure 8 shows the data model used to manage and organize the information stored in the system's database. Web services are formulated to run Structured Query Language (SQL) scripts for querying and entering data into the database.

\section{GSi Information Categories}

The GSi information contents are classified into different categories to organize geospatial contents systematically. This provides users with the option to group map layers based on their set criteria. Furthermore, this facilitates the sharing of geospatial contents that the users are interested in using their customized WebGIS portals. The GSi information categories defined are the Map Data, Map Layers, 


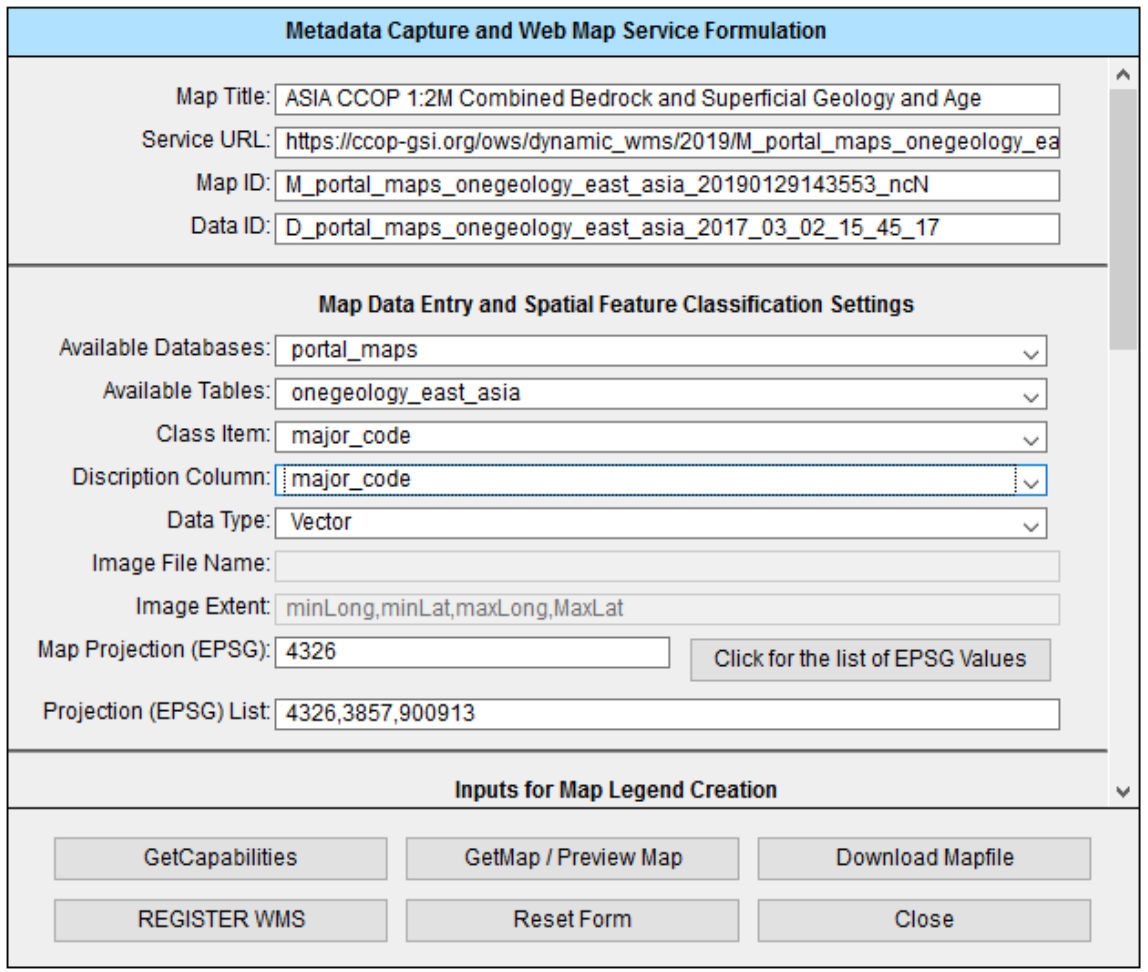

Figure 7. GSi form showing entries for the formulation of WMS for East Asia geological map.

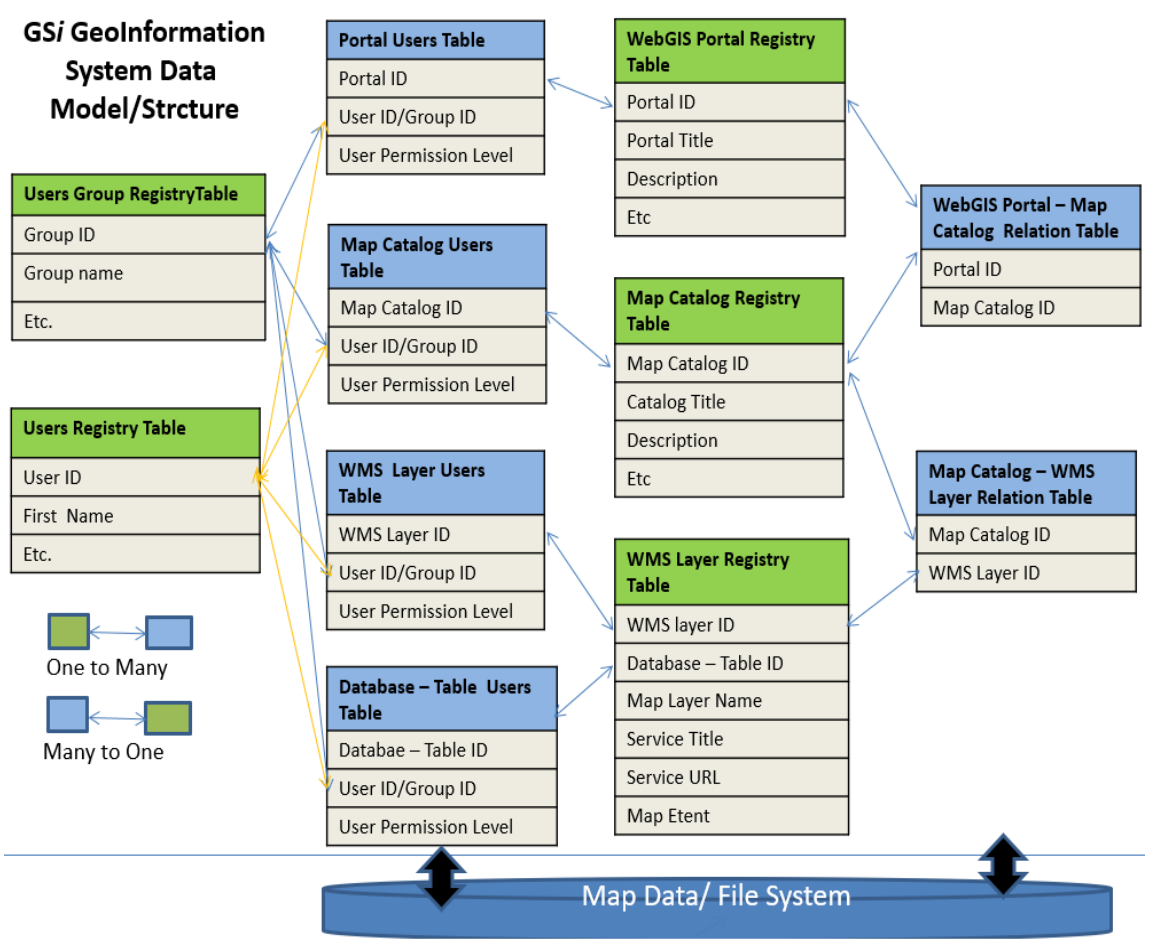

Figure 8. The GSi data model.

Map Catalogs and WebGIS Portals. Figure 9 shows the hierarchy of the information categories of the system. 


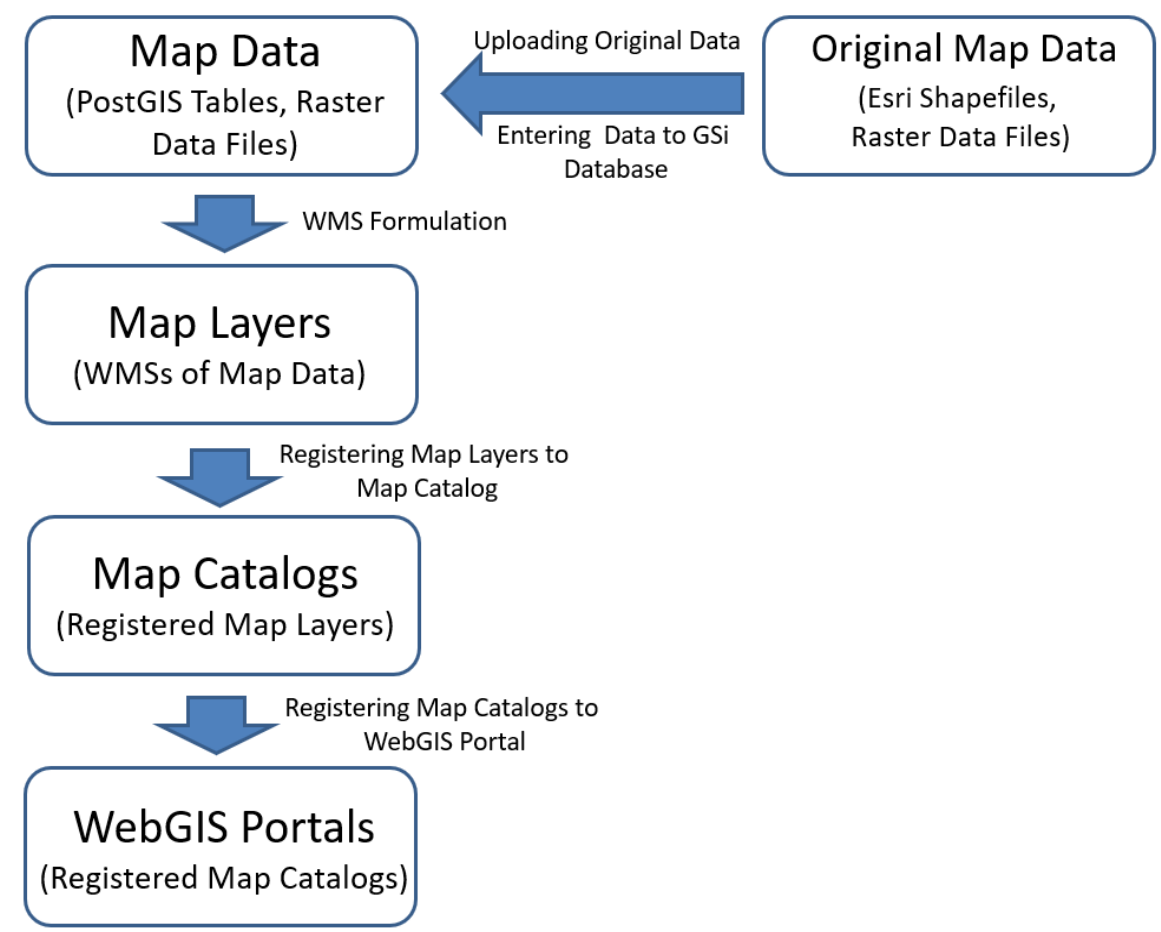

Figure 9. The hierarchy of the information categories of GSi.

\subsection{Map Data}

The information category Map Data represents the original map data uploaded and entered by the user to the GSi database (Figure 9). The original map data in vector format are stored as PostGIS table. Raster data are stored as files in the GSi server file system. GSi only accepts vector data in Esri shapefile format for entry into the GSi database. Raster data in GIF, TIF, JPG, PNG, GeoTif map images and ASTER satellite multi-band data in archive TAR.BZ2 formats can be uploaded to the GSi system.

\subsection{Map Layers}

The Map Layers are the WMSs formulated for the maps stored in the GSi database. Maps in the database can only be displayed in the WebGIS portal as WMS. Figure 7 shows the form for formulating WMS of the geological map covering East Asia. The map list displayed in the GSi portal (Figure 10) are the WMSs of the maps that are shared using the system.

\subsection{Map Catalogs}

The Map Catalogs are created to group map layers according to the users' criteria. They serve as map layer containers or folders. Researchers may create map catalog to group map layers that they need for their research. Mineral resource managers may create a map catalog containing mineral resources occurrence map layers. The ASEAN Senior Officials Meeting on Minerals (ASOMM) created the ASEAN Mineral map catalog as shown in Figure 11. 


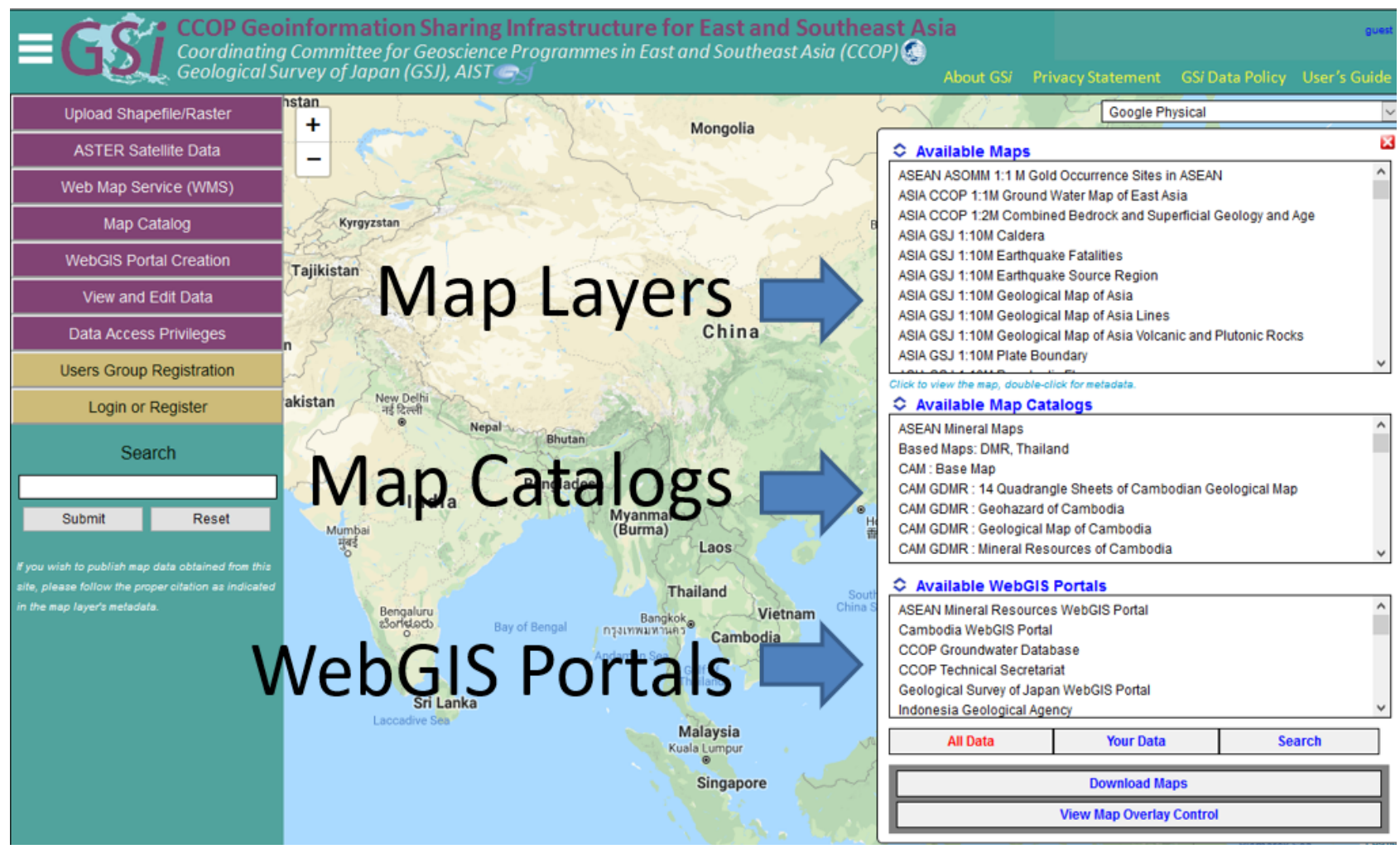

Figure 10. The list of the information categories displayed in the GSi main portal.

Map Layer to Map Catalog Registration

Available Map Catalog List

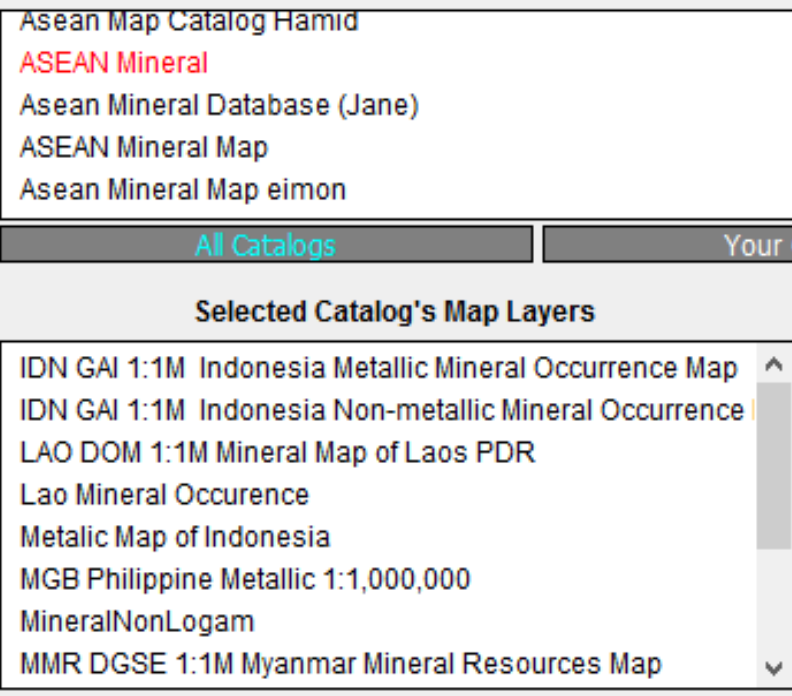

Remove Map Layer

\section{Your Catalogs}

Search

\section{Available Map Layers}

ASIA GSJ 1:10M Earthquake Fatalities

ASIA GSJ 1:10M Earthquake Source Region

ASIA GSJ 1:10M Geological Map of Asia

ASIA GSJ 1:10M Geological Map of Asia Lines

ASIA GSJ 1:10M Geological Map of Asia Volcanic and Pluton

ASIA GSJ 1:10M Plate Boundary

ASIA GSI 1.10M Purnclastic Fall - L atest

Your Layers

\section{Search}

Add Map Layer

Figure 11. GSi user interface for registering map layers to a chosen map catalog.

\subsection{WebGIS Portals}

WebGIS Portals category are the customized websites that are generated using 
the GSi system. Users who wish to create a WebGIS portal for their data can create one on the fly using the information system. GSi provides the users option to tailor the geospatial contents and web-based platform according to their needs. ASOMM created the WebGIS portal of the ASEAN mineral resources (Figure 12) using the system. The website shows the registered catalog ASEAN Mineral Maps, which contains the mineral occurrence maps of the countries in ASEAN.

\section{GSi User Information Access Privileges}

The GSi system provides data owners the option to control the access level of a user or group of users to the system information categories (i.e. map data, map layers, map catalogs and GSi generated WebGIS portals). The access level is expressed in terms of permission numbers which are the following:

$$
\begin{aligned}
& 4 \text {---- > Read } \\
& 2 \text {---- > Write/Edit } \\
& 1 \text {---- > Download }
\end{aligned}
$$

The combination of the 3 permission numbers results into 8 different permission numbers which are defined as follows:

$7(4+2+1)--->$ All privileges (i.e. Read, write and download).

$6(4+2)--->$ Read and write but not allowed to download.

$5(4+1)-->>$ Read and download but not allowed to write.

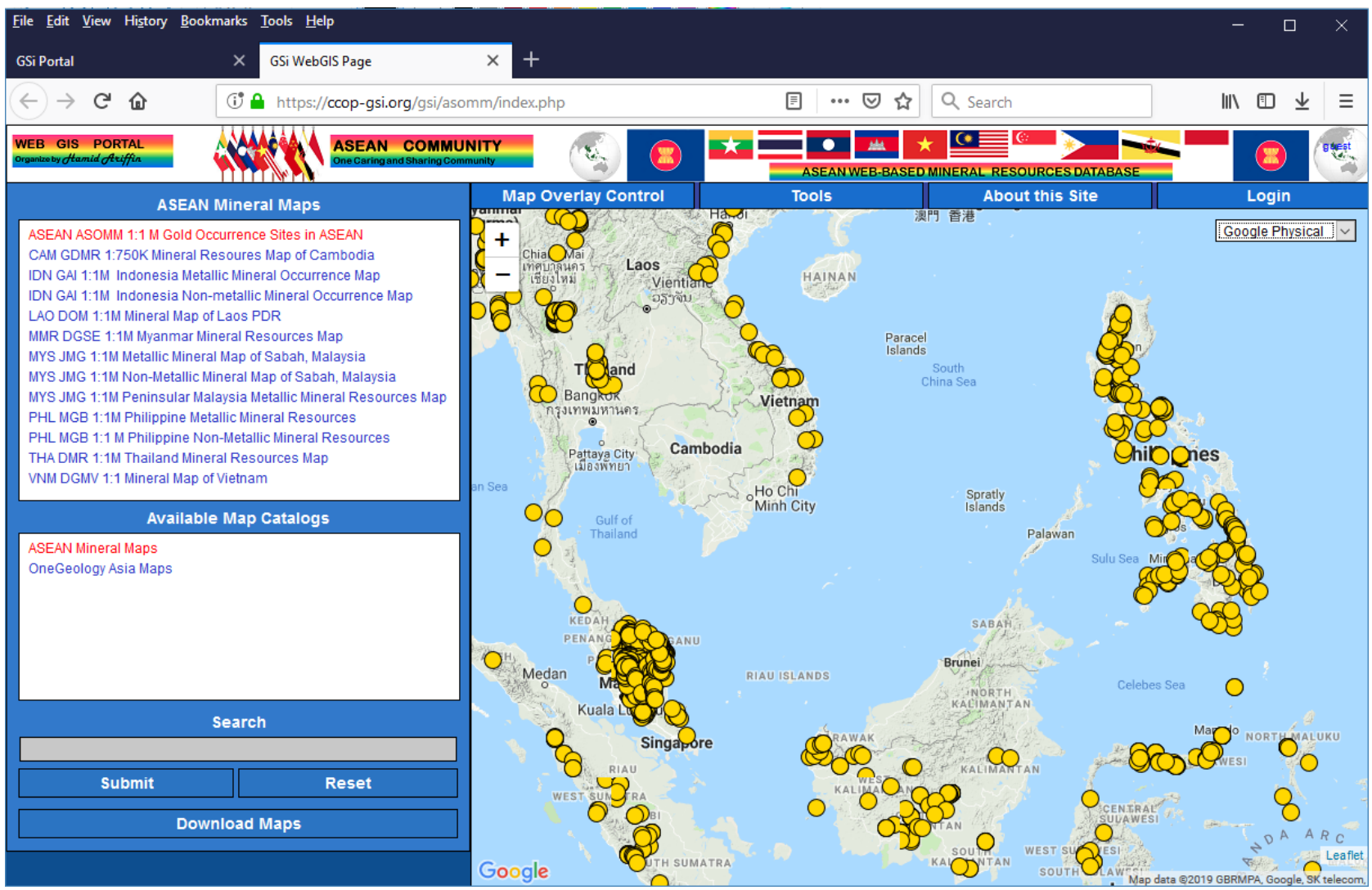

Figure 12. GSi generated ASEAN mineral resources WebGIS portal. 
4 ---> Read only.

$3(2+1)--->$ Write and download but not allowed to read.

2 ---> Write only.

$1-->$ Download only.

$0--->$ No privilege.

The option to assign permission number to GSi information categories provide data owners the flexibility on how to share their data to users or group of users. Some countries share some of their data only for viewing (permission number 4) because of some national law restrictions. On the other hand, other data owners only provide some selected research groups full access (permission number 7) to their data. The public is given permission number 4 to most information categories of GSi. The GSi permission number concept makes the information system acceptable to many countries with different national policies for sharing geoscience information to the public.

\section{Data Download}

GSi provides a user many options for the file format of the data to be downloaded. However, the availability of the file formats is dependent on the data access permission number of the user. All file formats are available if the user has data access permission number 5 or 7 . This includes the original data in Esri shapefile or the original raster data. A user whose permission level is restricted only for viewing, can just download data in PNG, PDF and KML formats. KML is just used as a client in displaying a map served as WMS.

\section{Discussion}

GSi is developed for the sharing of geoscience information among the countries in East and Southeast Asia and to the world. The information system provides interface and functions for users to easily access, process and download geospatial contents shared by the countries in the region. The GSi concept of sharing geospatial information through the OGC web services makes it possible for users to access and process spatial information from multiple sources. Furthermore, the classification of GSi information contents into several categories makes it convenient for the users to organize the accessed data according to their needs on their customized WebGIS portal. Several WebGIS portals generated by the information system presents geospatial contents that are very useful to many users. These include the ASEAN Mineral Resources WebGIS Portal, CCOP Groundwater Database and One Geology Portal Covering East Asia. Countries participating in the project also create their own portal using the system. Thailand provides a comprehensive presentation of the country's geospatial content using GSi generated WebGSI portal (Figure 13). The URLs of the portal sites can be found on the GSi main site (https://ccop-gsi.org/main/index.html). The option of the participating countries to determine the spatial data access privilege of a user or group of users is another important feature of the sharing 


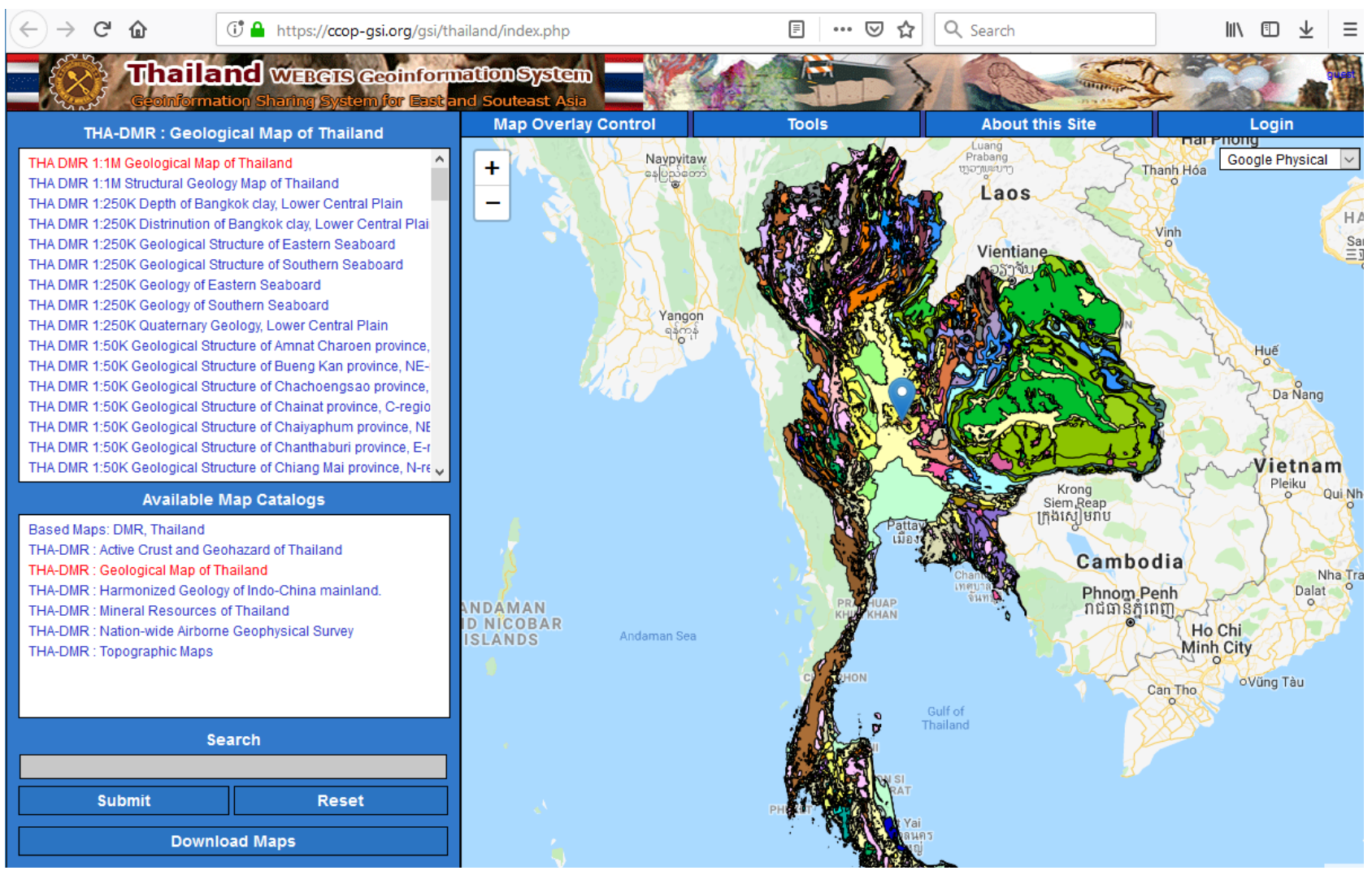

Figure 13. The WebGIS portal of Thailand generated using the GSi system.

system. This provides data owners the option to decide who can view, edit and download the geoscience information they share. This is a very important feature of the sharing system because data policies among the countries that are sharing data vary. Some countries may not completely share some of their data because of data copyright and national security issues, and just provide permission number 4 (view) to the general public. Other countries allow everybody to have full access to their data. The data access privileges concept makes GSi more acceptable to many countries with different national policies for sharing geoscience information to the public.

The development of the geoinformation sharing system is a project implemented by the Coordinating Committee for Geoscience Programmes in East and Southeast Asia (CCOP) and the Geological Survey of Japan (GSJ). The project is participated by the countries in the region. One of the major disadvantages of using the system is that data owners and users should be aware of the concept of web services such as WMS. Without WMS, it is very difficult to share the map data because viewing maps efficiently online requires the use of this web service. WMS is a new concept to many users making its formulation difficult. Because of this, CCOP and GSJ organize trainings on web service formulation and spatial data management. The main portal of the information system also provides comprehensive guide on how to use the system including the formulation of WMS. The information system was officially launched on September 17, 2018 in 
Langkawi, Malaysia. GSi is presently sharing more than 570 maps from countries in the region. These spatial data include geological, mineral resources, groundwater, geological hazards, seismic and active fault maps. ASTER satellite images are also shared using the information system. The satellite data are provided by METI AIST Data Archive System [31]. GSi, being an SDI can also be used as a source of web services and geospatial contents for a wide array of applications. Anyone can develop application and make GSi as the data source through its web services.

\section{Conclusion}

The sharing system for geoscience information for the countries in East and Southeast Asia called GSi, is successfully developed and operational. The use of SDI model, OGC web services and FOSS makes the GSi system very flexible, efficient and cost-effective. The classification of GSi's information contents into different categories and the definition of the access privileges of a user or group of users to these information categories, provide data owners the option to determine who can view, download and edit the information they share. These are very important features of a web-based map data sharing system. GSi also provides users with the tool to create their own customized WebGIS portal, which allows them to share their selected geospatial contents using their own web-based platform. Many users are presently using GSi in sharing their data making the information system an important source of data for environmental protection, disaster mitigation and the management and sustainable use of nature resources.

\section{Conflicts of Interest}

The authors declare no conflicts of interest regarding the publication of this paper.

\section{References}

[1] Huisman, O. and De, R. (2009) Principles of Geographic Information Systems. The International Institute for Geo-Information Science and Earth Observation (ITC), The Netherlands.

[2] Smith, M., Goodchild, M. and Longley, P. (2019) Geospatial Analysis, a Comprehensive Guide to Principles, Techniques and Software Tools. 6th Edition, The Winchelsea Press, Winchelsea, UK. https://www.spatialanalysisonline.com/extractv6.pdf

[3] Wei, Z., Gang, C., Hui, L., Huayang, L. and Huang, L.S. (2007) GIS Application in Mineral Resource Analysis-A Case Study of Offshore Marine Placer Gold at Nome, Alaska. Computers and Geosciences, 33, 773-788. https://doi.org/10.1016/j.cageo.2006.11.001

[4] Gongwen, W., Shouting, Z., Changhai, Y., Yaown, S., Yue S., Dong, L. and Fengming, X. (2011) Mineral Potential Targeting and Resources Assessment Base on 3D Geological Modeling in Luanchun Region, China. Computers \& Geosciences, 37, 1976-1988. https://doi.org/10.1016/j.cageo.2011.05.007 
[5] Ogunbadewa, Y.E. (2012) Development Natural Resources Database with Nigeriasat-1 Satellite Data and Geographical Information Systems. The Egyptian Journal of Remote Sensing and Space Sciences, 15, 201-214. https://doi.org/10.1016/j.ejrs.2012.04.002

[6] Prakash, P. (2017) Study the 2016 Flood Damages and Risk Assessment on Kedarnath, Himalaya Area Using Geoinformatics Techniques. Journal of Geography and Natural Disasters, 8, 216.

[7] Alqarni, S., Babiker, A. and Salih, A. (2018) Detection, Mapping and Assessment Change in Urban and Croplands Area in Al-Hassa Oasis, Eastern Region in Saudi Arabia Using Remote Sensing and Geographic Information System. Journal of Geographic Information System, 10, 659-685.

https://doi.org/10.4236/jgis.2018.106034

[8] Steinke, V.A., Barbosa, S.M., Mendes, V.J., Zanatto, V.G., Pessoa, G.E. and Bayma, G. (2018) Spatial Analysis of Federal Protected Areas and Priority Areas for Biodiversity Conservation in Brazil. Journal of Geographic Information System, 10, 718-734. https://doi.org/10.4236/jgis.2018.106037

[9] Trung, L.V. and Tam, D.M. (2018) Web GIS Solution for Monitoring the Forest-Cover in the Mekong Delta, Vietnam. Journal of Geographic Information System, 10, 491-502. https://doi.org/10.4236/jgis.2018.105026

[10] Lwin, K.K. and Murayama, Y. (2011) Web-Based GIS System for Real-Time Field Data Collection Using Personal Mobile Phone. Journal of Geographic Information System, 3, 382-389. https://doi.org/10.4236/jgis.2011.34037

[11] Sing, P.S., Chutia, D. and Sudhakar, S. (2012) Development of a Web Based GIS Application for Spatial Natural Resources Information System Using Effective Open Source Software and Standards. Journal of Geographic Information System, 4, 261-266. https://doi.org/10.4236/jgis.2012.43031

[12] Anderson, F. and Al-Thani, N.N.J. (2015) Feasibility Study of a National Web-Based GIS Application to Assess the Risk of Pesticide Drift in the U.S. Journal of Geoscience and Environmental Protection, 3, 20-24. https://doi.org/10.4236/gep.2015.37003

[13] Zerihun, M.E. (2017) Web Based GIS for Tourism Development Using Effective Free and Open Source Software Case Study: Gondor Town and Its Surrounding Area, Ethiopia. Journal of Geographic Information System, 9, 47-58. https://doi.org/10.4236/jgis.2017.91004

[14] Yang, C.P., Wong, D.W., Yang, R., Kafatos, M. and Li, Q. (2005) Performance-Improving Techniques in Web-Based GIS. International Journal of Geographical Information Science, 19, 319-342. https://doi.org/10.1080/13658810412331280202

[15] Gao, S. (2010) Advanced Health Information Sharing with Web-Based GIS. Ph.D. Dissertation, Department of Geodesy and Geomatics Engineering, Technical Report No. 272, University of New Brunswick, Frederiction, New Brunswick, Canada, 188 p.

[16] Chen, X., Ye, X., Carroll, M.C. and Li, Y. (2014) Online Flood Information System: REST-Based Web Service. International Journal of Applied Geospatial Research, 5 , 1-10. https://doi.org/10.4018/ijagr.2014040101

[17] Jian, J., Li, S., Wu, Z., Liu, Q., Hu, Y., Chen, S., Xu, Y., Liu, S., Liu, H. and Bai, K. (2012) Implementation of a WebGIS-Based Geological Environment Data Management Information System for Guangyuan City. Journal of Geology and Geosciences, 1, 1-4. 
[18] Charoenbunwanon, N., Wakita, K. and Bandibas, J.C. (2016) Web-Based Mineral Information System of Thailand Using Free and Open Source Software and Open Geospatial Consortium Standards: A Case Study of ASEAN Region. Geoinformatics, 27, 31-39. https://doi.org/10.6010/geoinformatics.27.2_31

[19] OGC. http://www.opengeospatial.org/standards

[20] Stefanakis, E. and Prastacos, P. (2008) Development of an Open Source-Based Spatial Data Infrastructure. Applied GIS, 4, 1-26.

[21] Nebert, D.D. (2004) Developing Spatial Data Infrastructure: SDI Cookbook Version 2.0. Global Spatial Data Infrastructure (GSDI), $171 \mathrm{p}$. http://gsdiassociation.org/images/publications/cookbooks/SDI_Cookbook_GSDI_2 004_ver2.pdf

[22] Steiniger, S. and Hunter, A.J.S. (2012) Free and Open Source GIS Software for Building a Spatial Data Infrastructure. In: Bocher, E. and Neteler, M., Eds., Geospatial Free and Open Source Software in the 21 st Century, Lecture Notes in Geoinformation and Cartography, Springer, Berlin, Heidelberg, 247-261. https://doi.org/10.1007/978-3-642-10595-1_15

[23] van der Wel, F.J.M. (2005) Spatial Data Infrastructure for Meteorological and Climatic Data. Meteorological Applications, 12, 7-8. https://doi.org/10.1017/S1350482704001471

[24] INSPIRE. https://inspire-reference.jrc.ec.europa.eu/vocabularies/scope/webgis

[25] Leaflet. https://leafletjs.com

[26] OGC. http://www.opengeospatial.org/standards/wms

[27] MapServer. http://mapserver.org/ogc/wms_server.html

[28] OGC. http://www.opengeospatial.org/standards/wps

[29] PostgreSQL. http://www.postgresql.org/about/

[30] PostGIS. http://postgis.refractions.net/

[31] MADAS. https://gbank.gsj.jp/madas/ 